\title{
Textual dynamism as a heuristic for a delicate semantic description of ellipsis patterns
}

\author{
Ben Clarke \\ University of Portsmouth \\ Park Building, King Henry I Street, Portsmouth, P01 2DZ, United Kingdom
}

This paper puts the case that viewing text dynamically can be valuable in the practice of semantic description. Using, as its case study, the statistically significant occurrence of Subject ellipsis across consecutive clauses in a corpus of newspaper football reports, the paper demonstrates a systematic difference between the lexicogrammatical characteristics of clauses containing such patterned use of ellipsis and the clauses of their surrounding co-text. The lexicogrammatical features in question, which are analysed in detail in the paper, are: clause length in words, number of clause elements, amount of syntactic embedding and patterns in Hallidayan transitivity process-types. Given the nature of these lexicogrammatical features, the argument is made that Subject ellipsis across consecutive clauses can iconically express an increase in pace something only observable when the text is viewed dynamically.

Keywords: Subject ellipsis, textual pace, textual dynamism, semantic description, lexicogrammatical features

Firth (1951: 123) famously remarked that linguistics is "language turned back on itself", that linguistic methods "are neither immanent or transcendent" but rather simply assist the linguist in her/his making statements of meaning. This paper is concerned with using the dynamic qualities observed in authentic language text as a heuristic for semantic description - specifically, here, the semantic description of a particular lexicogrammatical phenomenon: ellipsis. It takes, as its case study, the claim that the ellipsis of the grammatical Subjects across consecutive clause may express pace by iconic means (see Clarke, forthcoming). The paper begins, $\$ 1$, with a discussion of linguistic dynamism, starting with the Functional Sentence Perspective operationalisation of dynamism as a matter internal to the clause and then broadening the scope of dynamism to a wider textual environment (Danes, 1974; Matthiessen, 2002). In $\S 2$, ellipsis, the phenomenon under predominant focus in the paper, is defined and an argument made for the need for further work on more delicate semantic accounts of the phenomenon. $\S 3$ constitutes the mainstay of the paper. There, clauses attesting consecutive Subject ellipsis in a corpus of football newspaper reports are surveyed for their lexicogrammatical behaviour in respect of four features: (i) clause length in words; (ii) number of clause elements; (iii) amount of syntactic embedding; and (iv) transitivity. As the paper concludes, comparing the aforementioned features in those clauses implicated in the cases of consecutive Subject ellipsis with the clauses of the surrounding co-text suggests that ellipsis is used to convey pace - something only apparent when the analyst views the text dynamically.

\section{Clausal dynamism and textual dynamism}


In the Introduction to the present special issue, Clarke \& Arus loosely use 'linguistic dynamism' to refer to a range of ways in which different parts of some attested use of language contribute varyingly in the production of meaning. One of the earlier and more extensive attempts to account for what we may term 'linguistic dynamism' resides in the work of Firbas (e.g. 1971; 1992) and colleagues working in in Functional Sentence Perspective (henceforth FSP). What these scholars label 'communicative dynamism' (henceforth $C D$ ) is taken to be "an inherent quality of communication [... the] development towards the attainment of a communicative goal [...] the fulfilment of a communicative purpose" where "some elements are more or less dynamic", "differ[ing] in the extent to which they contribute to [that] further development of the communication" (Firbas, 1992: 7). For scholars in FSP, dynamism is primarily a matter internal to the clause; "the distribution of degrees of CD [is] over the sentence" (Firbas, 1971: 138) - these 'more or less dynamic' elements defined in terms of 'theme' (the lowest CD carrier) and 'rheme' (the highest carrier of CD). Daneš (1974) extends FSP's account of dynamism by considering how 'theme' patterns across complete texts; if most often the consecutive themes refer to the same referent, there is 'constant thematic progression'; if most often the rheme of one clause becomes the theme of the next, there is 'simple linear thematic progression'; etc..

While the starting point of Daneš (1974) 'thematic progression' is still an item defined in terms of its place within the clause, in 'logogenesis' Matthiessen (2002) proposes a notion of dynamism which is yet broader still. Matthiessen (2002) defines 'logogenesis' as an approach to text analysis which aims to account for how the text unfolds as a process in the creation of meaning. As such, it is concerned with dynamism across entire and organic textual environments. Counter to viewing the text synoptically and being concerned with - say - the ratio of positive polarity to negative polarity clauses in the text as a whole, a logogenetic analysis is sensitive to relative ordering in the evolution of semiosis which leads to the production of text; in terms of the same example, do either negative polarity or positive polarity clauses cluster, or otherwise predominantly occur at a certain point in the text? Conceiving of linguistic dynamism in this way, it relevant to inquire about the instantiated trajectory throughout the course of the text for any linguistic phenomenon, whether defined by a particular level (phonological, lexicogrammatical, semantic, etc.) or not, by a particular unit (text phase, clause, phoneme, etc.) or not. Something akin to the notion of 'logogenesis' is what is intended by dynamism in the present paper. This take on dynamism is relevant given that the phenomenon under study in this paper involves relations typically enacted across boundaries structurally greater than the clause complex (Halliday \& Hasan, 1976).

\section{Towards developing the description of the semantics of ellipsis}

This paper demonstrates the potential of the type of linguistic dynamism discussed in the last section to serve as a heuristic in the practice of semantic description. It uses, as its case study, Clarke (forthcoming), which is concerned with ellipsis - particularly the meanings expressed by ellipsis. Ellipsis, a lexicogrammatical phenomenon (Halliday \& Hasan, 1976: 89-90; Quirk et al., 1985: 859), is defined here as the predictable omission of one or more usually obligatory elements of some syntactic unit 'predictable' in that the elements in question can be retrieved from the co-text and can be specified in form precisely, pro-form and morphological variation aside (see Quirk et al., 1985: 884- 888 and Clarke, 2012: 64-66). Working in a broadly Hallidayan paradigm (Halliday, 1978; 1985; 1993; Halliday \& Hasan, 1985), Clarke (forthcoming) assumes a stratal and functional conception of language where the 
descriptive job relative to a lexicogrammatical phenomenon such as ellipsis is not complete until due consideration is given to the meanings it expresses and by which it is motivated (Barthes, 1977: 87; Halliday, 1979; 1996).

Only two such semantic accounts of ellipsis have so far been presented in the systemic functional literature. Halliday \& Hasan (1976: 306-308, 314-318) claim that ellipsis communicates 'continuity in the context of contrast'; that is, ellipsis conveys a local continuity (e.g. of referent, of process, etc.) where there is a broader environment of contrast (e.g. in terms of class membership, in terms of polarity or modality, etc.; see, for a more detailed discussion, Clarke, 2016b). However, so say Halliday and Hasan (1976: 306-308, 314-318), this is a generalised semantic motive for ellipsis - i.e. one common to all its uses. One-to-one grammar-meaning correspondences are rare in a system as complex as language (Givón, 1985). It is therefore very likely that more specific types and patterned uses of ellipsis will have their own different semantic motives for which a comprehensive description of ellipsis will also need to account.

The same argument is made by Xueyan (2013). In order to develop the descriptive account of ellipsis, Xueyan (2013: 239) calls for text-type specific studies of ellipsis - its patterns of use and meaning expressions in such text-types. She takes a step down this road by observing the use of ellipsis in textual data of a particular contextual type; namely, teacher-student interaction in EFL classroom discourse. However, in her data the only meaning she claims to be expressed by ellipsis is that which is expressed by instances of clausal ellipsis, which she shows are predominant in her data. These in her data, Xueyan claims, coherently tie together moves in the sequencing of such moves in dialogue. As a semantic expression, this is as general as Halliday \& Hasan's (1976: 306-308, 314-318) posited 'continuity in the context of contrast' meaning sense of ellipsis. Clarke (forthcoming), then, is the only published specific semantic statement on uses of ellipsis typical in a particular text-type known to the present author.

\section{Consecutive Subject ellipsis and textual pace}

Clarke (forthcoming) argues that instances of consecutive Subject ellipsis such as those in the following example relay, as a part of their meaning, a swiftness of pace.

(1) Craig Bellamy, whose contribution across the pitch was colossal, collected a Lescott interception, (Craig Bellamy [S]) ran 40 yards, (Craig Bellamy [S]) exchanged passes with Richards and (Craig Bellamy [S]) gratefully lashed in on 74 minutes.

(Week 5, Independent)

He uses, as his data, a 50,220 word corpus of eighty-nine newspaper reports on English Premier League football games played during 2009 and 2010 published on the websites of UK tabloid and UK broadsheet (for more details on the corpus, see Clarke, 2012; forthcoming). This dataset contains thirty cases of Subject ellipsis where there is also ellipsis of the Subject of the immediately preceding or subsequent clause (or both) - these thirty clauses giving fourteen examples like (1), twelve with two neighbouring cases of Subject ellipsis and two with three neighbouring cases of Subject ellipsis (three more of these are presented in $\S 3.1-3.4$; see Appendix 1 in Clarke forthcoming for the remaining ten). Given the 
occurrence of any type of ellipsis in this corpus, the occurrence of this particular patterned type is statistically significant $(p=0.000189)^{1}$.

The fundamental purpose of this section, the mainstay of the paper, is to demonstrate how linguistic dynamism of the sort described in $§ 1$ can assist in semantic description. If semiotic expression is typically complex such that meanings are often construed by an orchestration of multiple lexicogrammatical features (see the last section), any features identified as being sensitive to variation across local text environments may well become method and evidence for semantic description and semantic dynamism respectively (cf. again Firth, 1951: 123). To what semantic generalisation do such features appear to point? Not only must such inquiry be necessarily empirical (Xueyan, 2013: 239); the identification of the relevant lexicogrammatical features is, I here argue, facilitated significantly by the use of statistical computation.

This section is arranged into four parts, corresponding to four lexicogrammatical characteristics which suggest a systematic difference in examples like (1) between, on the one hand, the consecutive clauses containing Subject ellipsis and the antecedent clause (referred to collectively as 'the ellipsis clauses' in the following discussion) and, on the other, the clauses of the surrounding co-text - a difference seemingly motivated semantically so as to construe increased pace. First, $\$ 3.1$ considers the difference between the aforementioned groups of clauses in terms, simply, of their word length. Next, $\S 3.2$ and $\S 3.3$ look similarly at an assumed notion of 'text-time' but in more linguistically sophisticated terms - as a matter of the number of elements per clause and then the amount of syntactic embedding per clause. Finally, $\$ 3.4$ compares the ellipsis clauses with the clauses of the surrounding co-text in terms of patterns of transitivity, a different lexicogrammatical feature in type from those considered in the previous three sub-sections.

\subsection{Clause length in words}

Barthesian structuralists working on literary narrative (e.g. Barthes, 1966; Chatman, 1969; 1978; Genette, 1980; etc.) considered how the text can itself construe time, i.e. iconically - a vehicle to vary, emphasise and otherwise make meaningful aspects of time. In terms of durative meanings, for example, Chatman (1978: 72) labels textual 'stretch' instances where the reported actions happen in a short real-world timeframe (the 'story-time') but are discussed at great length in the text (the 'text-time'). Their approach can be criticised, most obviously owing to the page's indelicacy as a unit of measure for the assumed 'text-time' (see below this sub-section). Certainly, the page is better suited to the literary works with which those scholars were concerned; in the analyses of this paper, the page is an unsuitable measure, given the word length of texts in the football newspaper reports corpus introduced above is typically between

\footnotetext{
1 With four thousand seven hundred and thirty two clauses in the corpus and two hundred and forty four instances of any type of ellipsis, the chance of any clause containing ellipsis is slightly greater than five per cent $(244 / 4732=0.0516)$. The chance of two consecutive clauses both containing ellipsis is slightly greater than a quarter of $1 \%(0.0516 \times(0.0516 / 4642) \times 4643=$ 0.00264651). While of course semiotic relations are not random (Oakes, 1998), the occurrence of fourteen cases of consecutive ellipsis, all of the same Subject ellipsis type, is a particularly marked occurrence.
} 
300 and 800 words long. In an analysis akin to that of the aforementioned scholars, then, this sub-section uses clause length in words as a more delicate measure of 'text-time'?

Let us take another prototypical example of consecutive Subject ellipsis from the data, including some of its surrounding co-text:

(2) Keane is a player who thrives on confidence ${ }^{-3}$ and did not allow that to knock his nerve. ${ }^{-2}$ In the 18 th minute, he got the ball rolling - the ball he would eventually take home after his superb display - when he scored from the spot in ebullient fashion. ${ }^{-1}$ Jermain Defoe exposed Andre Bikey's lack of manoeuvrability by rolling him with ease, only to be brought down by the central defender's despairing challenge. ${ }^{1}$ Keane skipped up, ${ }^{2}$ (Keane [S]) shimmied, ${ }^{3}$ (Keane [S]) fooled keeper Brian Jensen into diving right ${ }^{4}$ and (Keane [S]) coolly slotted the ball into the other corner. ${ }^{+1}$ Burnley are not a team to park the bus on their away travels, despite their obvious weakness at the back. ${ }^{+2}$ And they do have a bit of flair going forward, which is why they have won all three of their Premier League home games so far. ${ }^{+3}$ Manager Owen Coyle was convinced they should have been rewarded in the 26th minute when Steven Fletcher rammed the ball home after a clever Joey Gudjonsson flick.

(Week 7, News of the World)

The word length of both those clauses attesting the successive Subject-only ellipsis (introduced with 2, 3 and ${ }^{4}$, and emboldened) and the antecedent clause in this example (introduced with ${ }^{1}$ and emboldened) appear prima facie short (3, 1, 7 and 9 words). Comparing the average word length of all 'the ellipsis clauses' (8.56 words) with the same measure for all clauses in the football newspaper reports corpus (10.63 words) does not, however, reveal much in the way of difference. This is particularly true if one considers that the difference is at least influenced, if not fully accounted for, by the omission to words caused by the ellipsis itself (for a more detailed discussion, see Clarke, 2016b). Such a comparison, however, misses the point; if the argument is that consecutive Subject ellipsis projects a quickening of the textual pace, relativity is paramount; quicker than what? The relevant contrast is not between those clauses implicated in the successive Subject ellipsis and all other clauses elsewhere in the corpus; it is far more local than that.

The length of the three clauses prior to (introduced with ${ }^{-1},{ }^{-2}$ and ${ }^{-3}$ ) and the three clauses immediately after $\left({ }^{+1},{ }^{+2}\right.$ and $\left.{ }^{+3}\right)$ 'the ellipsis clauses' in text example (2) are significantly greater in word length $(9,29$ and 24; 20, 26 and 27 words) than those clauses involved in the ellipsis. This trend is general to all fourteen examples of the phenomenon in the corpus; there is a statistically significant difference between the average word length for clauses containing consecutive Subject ellipsis (again, 8.56 words) and the same for all clauses immediately before or after (16.40 words for the clauses in the pre-co-text; 16.51 words for the post-co-text; see Appendix 2 in Clarke, forthcoming for more details). With a t-score of 6.2916 and 125 degrees of freedom, the probability that these results are down to chance - rather than motivated by different underlying populations - is $p<0.0005$.

Measuring 'text-time' by word count has revealed a systematic pattern such that those clauses involved in consecutive Subject ellipsis are significantly and repeatedly shorter in length than clauses of the

\footnotetext{
2 No attempt is made here to account for 'story-time' - compare how long is a skipping up with how long is a shimming (see textual example (2)) - and so neither is any attempt made to compare an assumed 'text-time' with an assumed 'story-time'.
} 
surrounding co-text. However, as hinted at above, this sort of analysis can still be criticised for being unsophisticated from a linguistic standpoint; much like the page, the word carries limited linguistic regularity (Sinclair, 1991: 28-29, 41). For this reason, the next two sub-sections compare the 'text-time' of 'the ellipsis clauses' and the clauses of the surrounding co-text by means of a more linguistically rigorous analysis in terms of syntactic complexity: (i) by the number of clause elements, as a measure of syntactic complexity conceived as syntactic breadth (§3.2); and (ii) by the amount of syntactic embedding, as a measure of syntactic complexity conceived as syntactic depth (§3.3). These analyses are complimentary halves of one 'syntactic complexity' whole; that is, the number of elements a clause has is likely to co-vary with the amount of syntactic embedding it attests. Their separation into two separate sub-sections aids presentation but is a division of an artificial kind, as per the process of analysis itself.

\subsection{Number of clause elements}

Evidence from a number of studies in psycholinguistic approaches relate syntactic complexity to cognitive processing and reading-time (e.g. Noordman \& Vonk, 1994; cf. also Simpson, 2014). Processing-time generally and reading-time certainly bear some relation to the construal of time by iconic means (cf. the last section). Other things being equal, then, the fewer in number the elements in a clause, the quicker the implied text pace; by the same token, the greater the number of elements in a clause, the slower the implied pace of the text. Consider the following further example of the phenomenon under focus in this paper:

(3) -3 Once he shrugged off his nearest marker he cantered, unchallenged, into the penalty area ${ }^{-2}$ and steered the ball into the far corner of the net. ${ }^{-1}$ The exuberant Ashley Cole, virtually playing as a winger, was next to take up the baton. ${ }^{1} \mathrm{He}$ tamed a lofted pass, ${ }^{2}$ (he [S]) left a bewildered Lorik Cana on his backside, ${ }^{3}$ and (he [S]) poked in a fabulous goal. ${ }^{+1}$ The outstretched foot of Marton Fulop prevented a fourth only temporarily, ${ }^{+2}$ but Frank Lampard capitalised on more slack marking when he slid in Ashley Cole's tantalising cross. ${ }^{+3}$ Anelka's blistering shot suggested that whatever Bruce said at half-time was insufficient to limit the damage.

(Week 21, Guardian)

The three clauses implicated in consecutive Subject ellipsis, repeated below as (3ai) - (3aiii), contain, respectively, three, three and two clause elements following a functional interpretation of the syntax of the English clause akin, broadly, to a Hallidayan (Halliday, 1961; 1967-8; 1994) cum Quirkian (Quirk et al., 1995; Biber et al., 1999) approach. Where it occasionally departs from standard Hallidayan (Halliday, 1994) model, Fawcett's $(2000 ; 2008)$ systemic functional model is followed; the most significant discrepancy in the context of the present analysis is that embedded clauses are treated as direct elements of a matrix clause rather than as tactically related clauses subject to analysis in their own terms ${ }^{3}$ :

(i) ' $\mathrm{He}$ [S/ngp] ii tamed [MV] ${ }^{\mathrm{iii}}$ a lofted pass [C/ngp],

\footnotetext{
${ }^{3}$ Note that each new clause element is introduced with a superscript Roman numeral. Inside square brackets after each clause element are short-form labels to denote, firstly, the clause element in question ( $S=$ Subject; $F=$ Finite; MV = Main Verb; C = Complement; $\mathrm{A}=$ Adjunct) and, secondly, separated by a forward slash, its realisation in form ( $\mathrm{Cl}$. = clause; $\mathrm{ngp}=$ nominal group; pgp = prepositional group; adjgp = adjectival group; advgp - adverb group).
} 


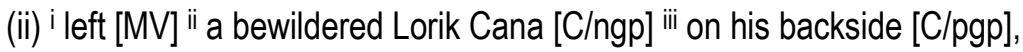

(iii) and i poked in [MV] ii a fabulous goal [C/ngp].

In comparison, the three clauses before those implicated in ellipsis, (3bi) - (3biii) below, have a greater number of clause elements - five, three, and four respectively:

(3b) (i) i Once he shrugged off his nearest marker [A/Cl.] "iihe [S/ngp] iii cantered [MV], iv unchallenged [A/adjgp], $\checkmark$ into the penalty area $[\mathrm{A} / \mathrm{pg}$ ]

(ii) and ' steered [MV] ii the ball [C/ngp] iii into the far corner of the net [A/pgp].

(iii) ${ }^{i}$ The exuberant Ashley Cole [S/ngp], ii virtually playing as a winger [A/Cl.], iii was [MV] iv next to take up the baton [C/adjgp].

The three clauses after 'the ellipsis clauses', (3ci) - (3ciii), also contain a greater number of clause elements with four, four and three respectively:

(3c) (i) ${ }^{i}$ The outstretched foot of Marton Fulop [S/ngp] ii prevented [MV] iii a fourth [C/ngp] iv only temporarily [A/advgp],

(ii) but ' Frank Lampard [S/ngp] ] ic capitalised on [MV] iii more slack marking [C/ngp] iv when he slid in Ashley Cole's tantalising cross [A/Cl.].

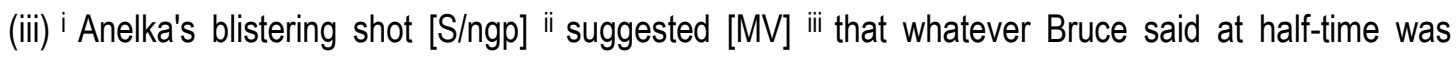
insufficient to limit the damage $[\mathrm{C} / \mathrm{Cl}$.].

This pattern - that the number of clause elements are fewer for 'the ellipsis clauses' than for the clauses of the surrounding co-text - is a trend general to all cases of consecutive Subject ellipsis in the football newspaper reports corpus. On average, clauses of the surrounding co-text have 4.46 clause elements, with, therein, clauses of the 'pre-co-text' having a slightly greater number of clause elements (4.58) than clauses of the 'post-co-text' (4.33). The average number of clause elements for those clauses involved in the cases of consecutive Subject ellipsis is fewer: 3.21 .

Although on first impression this difference appears to be minimal, the limits of working memory (Miller, 1956) mean that there is a ceiling on the size of even any motivated difference where numbers of clause elements are concerned; rather, what is important here is that the difference between 'the ellipsis clauses' and the clauses of the surrounding co-text is systematic; in twelve of the fourteen instances of consecutive Subject ellipsis in the data, there are, per clause, fewer clause elements in the ellipsis clauses' than there are for both the clauses of the 'pre-' and the 'post-co-text'. Neither is it the case that this difference in the number of clause elements is accounted for by the instances of Subject ellipsis contained within 'the ellipsis clauses'. For one thing, the clauses of the surrounding co-text contain ten ellipted clause elements themselves (e.g. (3bii) above). In addition, the average difference, in terms of numbers of clause elements, between 'the ellipsis clauses' and those clauses of the surrounding co-text across all fourteen examples is in excess of $1(4.46-3.21=1.25)$, and so cannot be explained by Subject ellipsis alone - even putting aside the not insignificant number of cases of ellipsis also in the clauses of the surrounding co-text. In sum of this sub-section, the clauses of the surrounding co-text appear more syntactically complex than 'the ellipsis clauses' in terms of the number of clause elements they contain. 


\subsection{Amount of syntactic embedding}

Syntactic embedding was described at the end of $\S 3.1$ as the depth of syntactic complexity. Let us here elaborate this description a little. Taking a Hallidayan (1961; see also Fawcett, 2008: 72-82) approach to grammar, syntactic units - regularities in form - are said to be composed of functional elements - parts of the unit defined by the role each plays in that unit. Each general type of syntactic unit (in English: clause, phrase and word) has its own functional elements. The English clause has the elements: Subject, Finite, Main Verb, Complement ${ }^{4}$ and Adjunct. Owing to the richness of this area of English grammar, there are a number of different types, or 'classes', of English phrase (noun phrase, verb phrase, adjective phrase, adverb phrase and prepositional phrase), each with their own inventory of functional elements (see, for example, Fawcett, 2000: 306-307). As often noted, present day English does little of its grammatical work morphologically; the number of functional elements needed to describe the syntactic unit of word in English are therefore few with syntactic embedding here rare. A case of syntactic embedding is said to occur, then, when an element of one syntactic unit has, as its form, a unit equal to or greater than itself on the rank-scale of syntactic units. By 'rank scale' is meant a hierarchy of units, bigger to smaller in typical size. In English, the rank-scale of syntactic units is: clause > phrase > word5; typically, a clause is composed of a number of phrases, a phrase of a number of words. In relation to an English phrase, for example, syntactic embedding happens when one of its elements takes either a clause or another phrase as its form (see below this sub-section for examples). One caveat needs imposing on this account of syntactic embedding. There are a small number of instances in English where syntactic embedding is an inevitable consequence of the grammatical environment, rather than being a free choice of the language user. Noun phrases which function as post-modifiers in prepositional phrases (e.g. backside in on his backside - see (3dii) below) would constitute just such a grammatical environment. These and equivalent cases of what may be termed 'obligatory' syntactic embedding will not be included as instances of embedding in the analyses of this section.

As was stressed at the end of $\S 3.1$, it is artificial to separate the discussions of the analyses of syntactic breadth and syntactic depth. To illustrate this point, compare (3ai) and (3ciii) from the last sub-section; both clauses have three clause elements, but one of these clauses is clearly more syntactically complex than the other (see below this sub-section) with that complexity furnished as syntactic depth, not breadth. As such, the analysis here of syntactic embedding considers the same example of consecutive Subject ellipsis as analysed for the number of clause elements in the last sub-section. In the analysis which follows, non-obligatory embedding of phrases within phrases is marked by enclosure of single square brackets (e.g. a [fabulous] goal) with non-obligatory embedding of a clause within either another clause or a phrase being marked by double square brackets (e.g. next [[to take up the baton]]). Given the relation between syntactic complexity and cognitive-processing (see the start of the last sub-section), the more

\footnotetext{
${ }^{4}$ Many non-Hallidayan functional models (e.g. Quirk et al., 1985; Biber et al., 1999) distinguish those arguments, Subject aside, which are new to the clause (so-called Objects; e.g. the ball in He picked up the ball) and subsequent mentions to a referent already present in the clause (so-called Complements; e.g. a study in frustration in Van Persie's face was a study in frustration).
}

${ }^{5}$ Where > denotes 'is greater than'. 
infrequent syntactic embedding, the quicker for implications of text pace and vice-versa - other things being equal.

(3d) (i) He tamed a i[lofted] pass,

(ii) left a i[bewildered] Lorik Cana on his backside,

(iii) and poked in a iffabulous] goal.

The three clauses implicated in consecutive Subject ellipsis, (3di) - (3diii), each have a single instance (a [lofted] pass, a [bewildered] Lorik Cana and a [fabulous] goal) of non-obligatory syntactic embedding - all unmodified adjective phrases functioning as pre-modifiers in a noun phrase. In comparison, the three clauses before those implicated in ellipsis, (3ei) - (3eiii), have three, two and three instances of syntactic embedding respectively:

(3e) (i) i[[Once he shrugged off his ii[nearest] marker]] he cantered, unchallenged, into the iii [penalty] area

(ii) and steered the ball into the [far] corner [of the net].

(iii) The i[exuberant] Ashley Cole, ii[[virtually playing as a winger]], was next iii[[to take up the baton]].

Likewise, for the three clauses following 'the ellipsis clauses', (3fi) - (3fiii), there are three, four and four instances of syntactic embedding:

(3f) (i) The i[outstretched] foot ii[of Marton Fulop] prevented a fourth iii[only] temporarily,

(ii) but Frank Lampard capitalised on [more ii[slack]] marking iii[[when he slid in Ashley Cole's iv[tantalising] cross]].

(iii) Anelka's iblistering] shot suggested ii[[that iii[[whatever Bruce said at half-time]] was insufficient iv[[to limit the damage]] ]].

This pattern - that there is notably less syntactic embedding in 'the ellipsis clauses' than in the clauses of the surrounding co-text - is common of all fourteen cases of the phenomenon under discussion. The average clause of the surrounding co-text has 4.26 cases of syntactic embedding. At 1.42 incidences of syntactic embedding, the average clause involved in the cases of consecutive Subject ellipsis has far less syntactic embedding.

As has been shown over the course of the analyses provided in the last two sub-sections, then, the analysis of syntactic breadth, as a matter of the number of clause elements, and the syntactic depth, as the amount of syntactic embedding, has revealed results which support the main finding of $\S 3.1$; that, namely, clauses involved in cases of consecutive Subject ellipsis behave markedly and systematically different to clauses of their surrounding co-text. However, the analyses of this sub-section and the last are more linguistically sophisticated than the relatively simple clause length in words analysis of $§ 3.1$.

\subsection{Patterns in transitivity}


A comparison of 'the ellipsis clauses' with those clauses of the surrounding co-text for the dynamic occurrence of a final lexicogrammatical feature provides yet further evidence for the claim that consecutive Subject ellipsis in this data is motivated by the semantics of a quickening of the textual pace. This analytical comparison is different in kind from those so far discussed in earlier parts of $\S 3$. Consider a third extended textual example from the data:

\footnotetext{
${ }^{-3}$ At that point, there seemed to be only one winner. ${ }^{-2}$ How wrong those doubters were as Ferguson's team surged back, Giggs the architect behind the comeback just as Arshavin had sparked Arsenal earlier.

${ }^{-1}$ The difference was referee Mike Dean said yes when United claimed their penalty as Rooney went crashing to the ground after Giggs had supplied the pass that sent him through one-on-on with Almunia.

${ }^{1}$ Rooney went straight for the ball, ${ }^{2}$ (Rooney [S]) put it on the spot ${ }^{3}$ and (Rooney [S]) promptly sent Almunia the wrong way. ${ }^{+1}$ When Diaby was hacked at by Rooney and Wes Brown, both men were booked ${ }^{+2}$ and Van Persie was offered the chance to curl a free-kick at Foster's goal which thudded against the crossbar. ${ }^{+3} \mathrm{~A}$ minute later, from a very similar position, United got their second when Diaby inexplicably headed into his own net.
}

(Week 4, Daily Star)

In this example, the two clauses containing the successive Subject ellipses (introduced with ${ }^{2}$ and ${ }^{3}$, and emboldened) and the antecedent clause (introduced with ${ }^{1}$ and emboldened) have dynamic main verbs (went for, put and sent). These are verbs of material transitivity in Halliday's (1967-8; 1994) terms - verbs denoting experiences observable to an on-looker as they are manifest outwardly of the body (cf. cognitive experiences, thinking, feeling, etc.). The main verbs which follow 'the ellipsis clauses' in this example (introduced with ${ }^{+1},{ }^{+2}$ and +3 ; booked, offered and got) are also all material process-types. However, the main verbs of those clauses preceding 'the ellipsis clauses' is very different, comprised of stative rather than dynamic verbs: in terms of Halliday's transitivity categories, seemed to be (introduced with ${ }^{-3}$ ) is existential; were (introduced with ${ }^{-2}$ ) is an attributive type of relational; and was (introduced with ${ }^{-1}$ ) is an identifying type of relational. An inversion of this pattern is seen in example (2) in §3.1 above: the main verbs of 'the ellipsis clauses' (skipped up, shimmied, fooled and slotted) along with those preceding 'the ellipsis clauses' (allow, got ... rolling and exposed) are material in transitivity, but the clauses subsequent to 'the ellipsis clauses' have a different transitivity profile: are is an attributive type of relational; have is a possessive type of relational; and convinced is mental. This pattern is common to all fourteen cases of consecutive Subject ellipsis and their surrounding clauses found in the football newspaper reports corpus. That is, the vast majority of clauses implicated in consecutive Subject ellipsis (79.55\%) have material transitivity. While there are still a predominant number of instances of material transitivity in the clauses of both the prior $(54.76 \%)$ and post co-text (56.10\%), this is less frequent than the occurrence of material transitivity in 'the ellipsis clauses'. Clauses of the prior and post co-text also share a significant frequency of relational transitivity ( $28.57 \%$ in the prior co-text; $31.71 \%$ in the post co-text) and so behave remarkably similarly in terms of their transitivity just as is the case in terms of their word length (see $\$ 3.1$ above).

\section{Conclusion}

The analytical trends presented in $\S 3.1$ - 33.4 establish a marked difference between, on the one hand, those clauses involved in cases of consecutive Subject ellipsis in the football newspaper reports corpus and, on the other, the clauses of their surrounding co-text - doing so in terms of the four 
lexicogrammatical features there discussed. 'The ellipsis clauses' are shorter (§3.1), syntactically simpler in having few clause elements (\$3.2) and less syntactic embedding (\$3.3), and are to a larger degree material in their transitivity (\$3.4). Indeed, it should be noted that these patterns are in all likelihood yet more pointed; the decision to take always and exactly three clauses of the surrounding 'pre-' and 'postco-text' against which to compare 'the ellipsis clauses' is arbitrary, designed to facilitate the analysis; these evidently will not be coterminous with organic rhetorical divisions of text and context (see, for example, Cloran, 1994; Gregory, 2002; etc.) where changes of temporal kinds, including pace, would be more naturally located. Regardless, these lexicogrammatical features do appear in a patterned way as just outlined. Moreover, in slightly different ways they have in common an ability to express time, whether most obviously by iconic $(\$ 3.1$ - §3.3) or denotational means (§3.4). For this reason, Clarke (forthcoming) claims that Subject ellipsis over consecutive clauses is motivated semantically by an intention to express a quickening of the textual pace. Given that a chief aspect of the social action of football newspaper reports is discussion of on-field events, this semantic reasoning appears to make good sense and perhaps explains the statistically significant frequency with which the phenomenon occurs in this data (see the introduction of §3). Greater support for the semantic sense of ellipsis discussed in Clarke (forthcoming) would, then, come from observing similar patterns of use of ellipsis in other text-types whose social action has experiential events associated with a range of paces, including fast ones. Further empirical work to this end is required. This paper's particular focus, though, has been a matter of how qualitative-in-kind, textual analyses which are sensitive to dynamism across local textual environments can, when combined with statistical inquiry, function as a descriptively powerful method for the linguist interested in making statements of meaning - an example of Firth's (1951: 123) famous dictum.

\section{References}

Barthes, R. (1966). 'Introduction à l'analyse structurale des récits'. Communications, 8, 1-27.

Biber, D., Johansson, S., Leech, G.N., Conrad, S., \& Finnigan. E. (1999). Longman Grammar of Spoken and Written English. London: Longman.

Chatman, S. (1969). 'New ways of analysing narrative structure'. Language and Style, 2, 3-36.

Chatman, S. (1978) Story and Discourse: Narrative Structure in Fiction and Film. Ithaca, New York: Cornell University Press.

Clarke, B.P. (2012). Do patterns of ellipsis in text support systemic functional linguistics' 'contextmetafunction hook-up' hypothesis? A corpus-based approach. PhD thesis, Cardiff University, Cardiff.

Clarke, B.P. (2016b) 'Cohesion in Systemic Functional Linguistics in the 21st century: A theoretical reflection'. In Bartlett, T \& O'Grady G. (eds.) The Routledge Handbook of Systemic Functional Linguistics. Oxford: Routledge.

Clarke, B.P. (forthcoming) 'Further semantics of ellipsis: The increased textual pace construed by consecutive Subject ellipsis'. Offered to Word. 
Cloran, C. (1994). Rhetorical Units and Decontextualisation: An Enquiry into some Relations of Context, Meaning and Grammar. Nottingham: Monographs in Systemic Linguistics.

Daneš, F. (1974). 'Functional Sentence Perspective and the organisation of the text'. In Daneš (ed.) Papers on Functional Sentence Perspective. The Hague: Mouton.

Fawcett, R.P. (2000). A Theory of Syntax for Systemic Functional Linguistics. Amsterdam: John Benjamins.

Fawcett, R.P. (2008). Invitation to Systemic Functional Linguistics through the Cardiff Grammar: An Extension and Simplification of Halliday's Systemic Functional Grammar. $3^{\text {rd }}$ edition. London: Equinox.

Firbas, J. (1971) 'On the concept of Communicative Dynamism in the theory of Functional Sentence Perspective'. In Sbornik praci filosofické fakulti brnenské universit,19/71, 135-144.

Firbaš, J. (1992). Functional Sentence Perspective in Written and Spoken Communication. Cambridge: Cambridge University Press.

Firth, J.R. (1951). 'Modes of meaning', Essays and Studies of the English Association, 4, 123-149.

Genette, G. (1980). Narrative Discourse. Oxford: Blackwell.

Givón, T. (1985). 'Iconicity, isomorphism and non-arbitrary coding in syntax.' In Haiman, J. (ed.) Iconicity in Syntax. Amsterdam: John Benjamins, 187-219.

Gregory, M.J. (2002) 'Phasal analysis within communication linguistics: Two contrastive discourses'. In Fries, P., M. Cummings, D. Lockwood \& W. Spruiell (eds.) Relations and Functions within and around Language. London: Continuum, 316-345.

Halliday, M.A.K. (1961). 'Categories of the theory of grammar'. Word, 17, 241-292.

Halliday, M.A.K. (1967-8). 'Notes on transitivity and theme in English, Parts 1-3'. In Journal of Linguistics, 3 (1), 37-81, 3 (2), 199-244 and 4 (2), 179-215.

Halliday, M.A.K. (1978). Language as Social Semiotic: The Social Interpretation of Language and Meaning. London: Arnold.

Halliday, M.A.K. (1979). 'Modes of meaning and modes of expression: Types of grammatical structure, and their determination by different semantic functions'. In Allerton, D.J., E. Carney \& D. Holdcroft (eds.) Function and Context in Linguistic Analysis: Essays Offered to William Haas. London: Cambridge University Press, 57-79.

Halliday, M.A.K. (1985). 'Systemic background'. In Benson, J.D. \& W.S. Greaves (eds.) Systemic Perspectives on Discourse. Norwood, New Jersey: Ablex, 1-15. 
Halliday, M.A.K. (1993). 'Systemic theory'. In Asher, R.E. (ed.) The Encyclopedia of Language and Linguistics. Oxford: Pergamon Press, 4505-4508.

Halliday, M.A.K. (1994). An Introduction to Functional Grammar. 2nd edition. London: Arnold.

Halliday, M.A.K. (1996). 'On grammar and grammatics'. In Hasan, R., C. Cloran \& D.G. Butt (eds.) Functional Descriptions: Theory in Practice. Amsterdam: John Benjamins, 1-38.

Halliday, M.A.K. \& Hasan, R. (1976). Cohesion in English. London: Longman.

Halliday, M.A.K. \& Hasan, R. (1985). Language, Context and Text: Aspects of Language in a Social Semiotic Perspective. Oxford: University Press.

Matthiessen, C.M.I.M. (2002). 'Lexicogrammar in discourse development: Logogenetic patterns of wording.' In Huang, G. \& Wang, Z. (eds.) Discourse and Language Functions. Shanghai: Foreign Language Teaching and Research Press, 2-25.

Noordman, L \& Vonk, W. (1994). 'Text processing and its relevance for literacy'. In Verhoeven, L (ed.) Functional Literacy: Theoretical Issues and Educational Implications. Amsterdam: John Benjamins, 7592.

Oakes, M. (1998). Statistics for Corpus Linguistics. Edinburgh: Edinburgh University Press.

Quirk, R., Greenbaum, S., Leech, G. \& Svartvik, J. (1985). A Comprehensive Grammar of the English Language. Harlow: Longman.

Simpson, P. (2014). 'Just what is narrative urgency?' Language and Literature, 23: 1, 3-22.

Sinclair, J. (1991). Corpus, Concordance, Collocation. Oxford: Oxford University Press.

Xueyan, Y. (2013). 'Modelling ellipsis in EFL classroom discourse'. In Yan, F. \& Webster, J.J. (eds.) Developing Systemic Functional Linguistics: Theory and Application. Sheffield: Equinox, 227-240. 